\title{
LA DIVERSIDAD LINGÜÍSTICA DE COSTA RICA: LAS LENGUAS INDÍGENAS ${ }^{1}$
}

\author{
Adolfo Constenla Umaña
}

\begin{abstract}
RESUMEN
Este trabajo, según lo solicitado por los organizadores de la Primera Semana de la Diversidad Lingüística, trata el origen de las lenguas amerindias de Costa Rica, cuáles de ellas se encontraban en su territorio en la época precolombina, cuáles se encuentran ahora y en qué situación están, y, finalmente, qué ha tomado de ellas la lengua dominante en el país en la actualidad: el castellano local. Palabras clave: lenguas amerindias de Costa Rica, filiación lingüística, época de establecimiento en el territorio, estado de conservación, influencia sobre el castellano local.
\end{abstract}

\begin{abstract}
This paper as requested by the organizers of the First Week of Linguistic Diversity, deals with the origin of the Amerindian languages of Costa Rica, which were already in its territory at the pre-Columbian time, which are found currently, and what is their state, and, finally, what kind of elements were borrowed from them by Spanish, the dominant language of the country.

Key words: Costa Rican Amerindian languages, linguistic filiation, time of establishment in the territory, retention state, influence on local Spanish.
\end{abstract}

\section{Un vistazo general a la historia lingüística de Costa Rica}

Antes de entrar directamente en materia, para que los hechos relativos a las lenguas indígenas que se tratarán luego con más detalle queden situados en un panorama general, ofreceré la siguiente síntesis de la historia lingüística de Costa Rica (basada en Constenla Umaña 2006: 256).

Con anterioridad al siglo IX d. C. en este país se hablaban únicamente lenguas chibchenses: el guatuso y el rama (voto, corobicí) en las llanuras del norte y en Guanacaste, el huetar -considerado por los españoles la "lengua general" de Costa Rica al momento de su

Dr. Adolfo Constenla Umaña. Profesor emérito. Universidad de Costa Rica. Correo electrónico: aconsten@ice.co.cr

Recepción: 12- 03- 2012

Aceptación: 20- 04- 2012 
llegada- en el Valle Central y sus alrededores, el boruca en la vertiente pacífica sur, el cabécar en la vertiente atlántica central y el oeste del actual cantón de Talamanca (al sudeste del país) y el bribri tanto en el oeste como en el este de este mismo cantón. Todo el territorio costarricense pertenecía a un área lingüística que he denominado Área Colombiano-centroamericana y que coincide bastante bien con la arqueológica llamada Baja Centroamérica.

Durante el siglo IX, hablantes del chorotega, una lengua otomanguense, se apoderaron de la mayor parte del noroeste de Costa Rica, que pasó a pertenecer al Área Linguística Mesoamericana. Posteriormente, otros mesoamericanos, en este caso hablantes de nahua (familia aztécica, estirpe utoaztecense), penetraron en territorio costarricense tras haberse arraigado en Nicaragua en el siglo XIII y establecieron por lo menos un pequeño enclave en Bagaces, Guanacaste.

La conquista española en el siglo XVI inició un proceso de expansión del castellano que se completó en el siglo XX. El castellano no fue la única lengua que entró a Costa Rica o se extendió por ella a partir de aquel momento. A fines del siglo XVII, los hablantes del térraba - una de las dos variedades de la lengua naso (el teribe es la otra)- inmigraron al sudoeste de Costa Rica desde el noroeste de Panamá.

Durante la segunda mitad del siglo XIX, hablantes del criollo de base inglesa del Caribe occidental, sobre todo de Jamaica, se establecieron en la costa atlántica. A fines del siglo XIX, hablantes del bribri y del cabécar inmigraron desde la zona atlántica a las faldas de la vertiente pacífica de la Cordillera de Talamanca. Finalmente, en la segunda mitad del siglo XX, empezó la inmigración desde Panamá de hablantes de guaimí.

Por supuesto que ha habido hablantes de otras lenguas que han penetrado en Costa Rica (como misquito, cantonés, yídish o gallego), pero en esta exposición solo tomo en cuenta las que llegaron a constituirse, durante algún tiempo por lo menos, en lenguas territoriales. Debo aclarar que el concepto lengua territorial se refiere a la lengua materna de un grupo de habitantes de un territorio en el cual es usada normalmente por ellos al menos en parte de las situaciones comunicativas.

La expansión del castellano inició también un proceso de reemplazo de las lenguas indígenas. Durante la colonia se extinguieron el nahua (probablemente ya en el siglo XVII), y el chorotega y el huetar (en el siglo XVIII), esto debido a que en las zonas en que se hablaban se dio la colonización más intensa en aquel tiempo. El rama se extinguió en Costa Rica hacia 1930. Los últimos hablantes fluidos de térraba y de boruca murieron en la primera mitad de la década pasada.

En nuestro país, las lenguas territoriales que se han dado de acuerdo con lo antes expuesto pertenecen a las siguientes agrupaciones linguiísticas genealógicas: estirpe chibchense, estirpe otomanguense, estirpe utoaztecense y estirpe indoeuropea (subagrupaciones románica y germánica). Las primeras tres, por ser las indígenas, son aquellas de las que nos corresponde ocuparnos en esta charla. Pasamos ahora a ver qué nos dice la aplicación de los métodos de la lingüística diacrónica en su caso.

\section{Las lenguas de establecimiento más antiguo: las chibchenses}

De acuerdo con lo antes expuesto, con anterioridad al siglo IX d.C. las lenguas presentes en el territorio costarricense de cuya existencia se tienen indicios eran todas chibchenses. ¿Cuál es el origen de estas lenguas, las de establecimiento más antiguo en él, y cómo llegaron hasta acá? 
En el momento de la llegada de los españoles a América, la estirpe chibchense incluía con seguridad 23 lenguas extendidas por un territorio que va de Honduras hasta la zona fronteriza de Venezuela con Colombia en los estados de Zulia y Apure. Estas lenguas, de las cuales 15 tienen todavía hablantes fluidos, son las siguientes (además de los nombres que se usarán a lo largo del artículo, entre paréntesis se incluyen nombres alternativos que se les dan o han dado):

1) Paya (pech), 2) Rama, 3) Guatuso (malecu), 4) Huetar, 5) Cabécar, 6) Bribri, 7) Boruca, 8) Naso (teribe/térraba), 9) Chánguena, 10) Dorasque, 11) Guaimí (ngäbere, movere), 12) Bocotá (guaimí sabanero, buglere), 13) Cuna (tule), 14) Antioqueño, 15)Chimila(ettetaara),16)Cogui (cágaba),17)Damana (guamaca,sanká,arsario,malayo, marocasero, wiwa), 18) Atanques (kankuama), 19) Ica (arhuaco, bíntucua), 20) Barí (motilón, dobocubí,cunaguasaya),21)Tunebo(uwa),22)Duit,23)Muisca(mosca,chibcha)

La siguiente es mi clasificación o subagrupación actual de las lenguas chibchenses (Constenla Umaña 2008: 127-128):

A. Paya.

B. Chibchense nuclear:

B.1. Vótico: Rama, guatuso, [huetar].

B.2. Ístmico:

B.2.1. Ístmico occidental:

B.2.1.1. Viceítico: cabécar, bribri.

B.2.1.2. Naso (teribe/térraba).

B.2.1.3. Boruca.

B.2.2. Dorácico: dorasque, chánguena.

B.2.3. Ístmico oriental:

B.2.3.1. Guaimíico: guaimí, bocotá.

B.2.3.2. Cuna.

\section{B.3. Magdalénico:}

B.3.1. Magdalénico meridional:

B.3.1.1. Chibcha: muisca, duit.

B.3.1.2.Tunebo.

B.3.1.3. Barí.

B.3.2. Magdalénico septentrional:

B.3.2.1. Arhuácico:

B.3.2.1.1. Cogui.

B.3.2.2. Arhuácico oriental-meridional:

B.3.2.2.1. Arhuácico oriental: damana, atanques.

B.3.2.2.2. Ica.

B.3.2.2.3 Chimila. 
Las lenguas chibchenses estaban distribuidas para la época de la llegada de los españoles en cuatro regiones discontinuas (Constenla Umaña 1995: 43-44): a) el territorio de los payas en el oriente de Honduras, b) el territorio que se inicia en el extremo sur de la costa atlántica nicaragüense con los ramas y se prolonga hasta el oeste de Panamá en el que se daba una cadena continua de pueblos chibchenses, c) el territorio que se inicia en el área fronteriza entre Panamá y Colombia (entre los ríos Tuira y Atrato y el Golfo de Urabá) habitada por los cunas y contigua a la habitada por los nutabes y catíos chibchenses en el departamento de Antioquia, y d) el territorio situado al este del Magdalena, en que pareciera haber existido una cadena continua de pueblos chibchenses que se extendía desde Cundinamarca hasta la Sierra Nevada de Santa Marta y cuya parte intermedia se extendía por el departamento de Norte de Santander y luego por la Sierra de Perijá. El primero de estos territorios estaba claramente separado del segundo por pueblos de la familia misumalpa que ocupaban la mayor parte de la Nicaragua central y atlántica; el segundo quedaba aislado del tercero por el este de Panamá, ocupado por los cuevas, y, finalmente, entre el tercero y el cuarto se interponían pueblos caribes como los opones o de presuntas afinidades caribes como los muzos, panches y pijaos.

El segundo de estos territorios, al que me referiré con el término central, es aquel en que se da el mayor grado de diversidad y de entrecruce de límites de cambios lingüísticos. Es un principio de la teoría lingüística de las migraciones que "las migraciones positivas determinables se dan de las áreas complejas a las uniformes” (Dyen 1956: 625). Una migración positiva es, normalmente, la de un grupo de hablantes de una misma lengua (los hablantes de distintas lenguas no suelen emigrar juntos) desde el territorio original de una familia lingüística, es decir, de un territorio en el que ya hay fragmentación lingüística. Al alcanzar el nuevo territorio, el grupo puede fragmentarse, pero dado que esta fragmentación es más reciente que la que existe en el territorio original de la familia, la diversificación será menor. En la parte de Colombia situada al este del Magdalena, que por el número de lenguas que incluye es el otro territorio que a primera vista podría plantearse como originario, se presenta una diversificación claramente menor que la que se da en el territorio central.

De acuerdo con lo anterior, del territorio central, deben de haber partido las migraciones que llevaron primeramente a los antepasados de los pueblos chibchenses de Colombia y Venezuela hacia el este.

Hasta hace relativamente poco tiempo, en el caso de la lengua chibchense situada más hacia el norte, el paya de Honduras, cabían dos posibilidades. Una de ellas era que, al igual que las lenguas chibchenses de Colombia y Venezuela, hubiera emigrado desde el territorio central a su localización actual. La otra era que el subantepasado de todas las otras lenguas chibchenses se hubiera separado de él en Honduras y emigrado desde allí hacia el territorio central. Hasta comienzos del pasado decenio no había argumentos contundentes a favor de una u otra. Sin embargo, en la primera mitad de dicho decenio se demostró (Constenla Umaña 2005) el parentesco entre la estirpe chibchense y otras dos agrupaciones genealógicas de la Baja Centroamérica: la familia lenca (de Honduras y El Salvador) y la familia misumalpa (de Honduras y Nicaragua). Las tres agrupaciones constituyen un microfilo para el que se ha propuesto el nombre lenmichí y el territorio original del antepasado común a todas las lenguas que las componen, el protolenmichí, de acuerdo con los principios antes mencionados de la teoría lingüística de las migraciones tiene que haber estado en Honduras. Esta conclusión lingüística resulta muy acorde con las propuestas arqueológicas según las cuales hace unos 11 850 años, hacia el año 9840 a.C., se habrían establecido en Honduras sus primeros habitantes que serían también los primeros de la América Central. 
La aplicación de la glotocronología, método de la lingüística diacrónica que permite establecer fechas aproximadas de la separación entre lenguas emparentadas, indica que la primera división del microfilo lenmichí, la separación entre el subantepasado común a las lenguas lencas y misumalpas y el subantepasado de las lenguas chibchenses, ocurrida en Honduras, se remonta a $9726 \pm 1105$ años antes del presente, o sea, $7715 \pm 1105$ a.C. El subantepasado de las lenguas lencas y el de las misumalpas se habrían separado alrededor de 7075 años antes del presente (5064 a. C.). La separación del paya y el subantepasado de las demás lenguas chibchenses se habría producido hacia los 6682 años antes del presente (4671 a. C.). La división del protochibchense meridional en protovótico, protoístmico y protomagdalénico empezó hace unos 5400 años, es decir 3400 a.C., época a partir de la cual habría empezado el establecimiento de las lenguas chibchenses en nuestro territorio. La división del protovótico en el guatuso y el rama se produjo muy tempranamente: hace unos 5000 años. La del protoístmico (subantepasado del bocotá, boruca, bribri, cabécar, chánguena, cuna, dorasque, guaimí y naso) habría empezado hace unos 4600 años y la del protomagdalénico (subantepasado del muisca, el duit, el tunebo, el barí, el chimila, el coqui, el damana, el atanques y el ica) hace unos 4100 años. Los datos anteriores nos indican lo distante que son las relaciones entre la mayor parte de las lenguas chibchenses. Para usar algún punto de comparación, en el caso de la familia maya, la "más diversificada y populosa de Mesoamérica", integrada por lo menos por 24 idiomas, la primera separación que se produjo, la "del huasteco del resto de la familia", data de "hace más de 2500 años" (Kaufman 1974: 34). El comienzo de separación entre las lenguas chibchenses, entonces, se produjo 4000 años antes de que empezara la separación entre las lenguas mayas.

Hay que señalar que en materia de relaciones externas, la estirpe chibchense ha sido propuesta como núcleo de un filo macrochibcha con miembros distribuidos desde Argentina (el allentiac) y Chile (el atacameño) hasta México (el tarasco) e incluso Florida, en los Estados Unidos de América (el timucua). Además, se le han atribuido relaciones con el filo hokense (Jijón y Caamaño 1943), con la familia maya, la estirpe caribe y la estirpe arahuaca (Schuller 1919/20), con la estirpe utoaztecense y la pano-tacana (Holt 1986), y con la mayoría de las lenguas indígenas de América (Greenberg 1987). Ninguno de estos otros parentescos propuestos se ha probado por medio de la aplicación sistemática del método apropiado de la linguiística diacrónica: el método comparativo.

\section{Las lenguas mesoamericanas}

\subsection{El chorotega}

El chorotega fue la primera lengua de origen mesoamericano en establecerse en Nicaragua y Costa Rica. La lengua chorotega, de la que nos quedaron materiales que abarcan unos 330 diferentes lexemas y cierto número de frases y cláusulas (todos ellos analizados en Quirós Rodríguez 1984), pertenece a la familia mánguica integrada por dos lenguas: el chorotega o mangue (que se extinguió en el siglo XVIII en Costa Rica y a fines del XIX en Nicaragua) y el chiapaneco (que se extinguió a mediados del siglo XX en Chiapas, México). Esta familia pertenece, a su vez, a la estirpe otomanguense, de cuyos miembros la totalidad, fuera del chorotega, se habla o habló en México (lenguas como el mixteco, el mazateco, las otomíes, las pames, las zapotecas, las chinantecas y el amuzgo). Los cálculos glotocronológicos sitúan entre los años 600 y 700 de la era cristiana la separación del chiapaneco y el chorotega producida por la partida de esta segunda lengua hacia América Central. 
Los chorotegas estuvieron establecidos en el departamento de Choluteca de Honduras, en el noroeste y centro del litoral pacífico de Nicaragua y, en el noroeste de Costa Rica, en toda la península de Nicoya y en un sector de la costa oriental del golfo de Nicoya situado aproximadamente entre el río Abangares y Chomes. Su llegada al istmo de Rivas es situada por los arqueólogos hacia 800 d. C. En Costa Rica se habrían establecido unos cien años después.

\subsection{El nahua}

De acuerdo con los indicios arqueológicos, los hablantes de nahua denominados nicaraos se establecieron en Nicaragua y Costa Rica con posterioridad al 1200 d.C. De oeste a este, se encontraban los nicaraos a) en varios enclaves en los departamentos nicaragüenses de Chinandega y León con alguna penetración en el departamento hondureño de Choluteca, b) en un territorio continuo que abarca aproximadamente los departamentos de Carazo, Rivas y parte del de Granada (o sea, la mayor parte de lo que queda entre el Lago de Nicaragua y el Océano Pacífico), c) en enclaves en la orilla este del Lago de Nicaragua, en el departamento de Chontales y d) en Bagaces y quizás otros enclaves de la Provincia de Guanacaste, Costa Rica.

El nicarao es un miembro de la familia aztécica (con una profundidad temporal de 1500 años) que a su vez forma parte de la estirpe utoaztecense (con una profundidad temporal de 4800 años). La primera escisión en la familia aztécica, originalmente establecida en Nayarit, México, se habría producido aproximadamente entre el 500 y el 550 d.C. y habría consistido en la separación entre el pochuteco, lengua de la costa pacífica de Oaxaca y el subantepasado de las demás lenguas de la familia, grupo denominado aztécico general, que a su vez se dividió hacia el 900 d.C. en el subgrupo de lenguas llamado nahua nuclear y el pipil de El Salvador y del sudoeste de Guatemala.

El examen de los escasos datos de nicarao indica que su relación era más fuerte con lenguas integrantes del nahua nuclear que con el pipil. En Costa Rica, el nicarao, aunque sí llegó a tener la condición de territorial, tuvo un número sumamente reducido de hablantes y era, en consecuencia, la lengua más minoritaria de todas las que se hablaban a la llegada de los españoles.

\section{Situación actual y estado de retención de las lenguas indígenas}

En la actualidad, las lenguas indígenas territoriales de Costa Rica son cuatro: bribri, cabécar, guaimí y guatuso. El censo realizado en el año 2000 tomó en cuenta las lenguas, pero solo en el caso de las poblaciones de las reservas indígenas. Los siguientes son los números de hablantes: 5963 de bribri (61,8\% del grupo étnico), 8441 de cabécar (84,5\%), 2172 de guaimí $(84,4 \%)$, y 276 de guatuso $(71,1 \%)$.

Los 16852 hablantes de estas lenguas constituyen el 74,8\% de la suma (22 529) de las poblaciones de los cuatro grupos en las reservas. En el censo, hubo 41347 personas más que declararon ser indígenas. Mi interpretación de los datos es que a lo sumo unos 9180 hablarían lenguas indígenas costarricenses territoriales. Había en Costa Rica, entonces, unos 26032 hablantes de lenguas indígenas territoriales, que constituían casi el $0,7 \%$ de la población del país (3 810179 en el año 2000).

Para comparar con las otras lenguas territoriales del país, señalaré que los hablantes del criollo de base inglesa serían el 1,3\% de la población del país. El castellano es la lengua territorial empleada por el $98 \%$ restante.

Como he señalado en un trabajo previo (Constenla Umaña 2006: 257), a pesar de algunas disposiciones que se han tomado en favor de las lenguas indígenas, todas las lenguas 
minoritarias del país se encuentran en peligro de extinción. De acuerdo con la clasificación de los estados de retención de las lenguas del lingüista estadounidense James Bauman (1980), la única lengua en estado floreciente en Costa Rica es el castellano; el cabécar y el guaimí en algunos de sus territorios pueden clasificarse como resistentes y las mismas lenguas en otros lugares, el bribri, el guatuso y el criollo limonense están en estado de declinación.

Contra las lenguas minoritarias pesan muchos factores. Sus hablantes constituyen minorías muy pequeñas que, en correspondencia, tienen poca influencia política. No se exige su dominio en ningún aspecto de administración pública y, en consecuencia, no dan ventajas a sus hablantes. Se usan solo en situaciones en las que todos los participantes son hablantes fluidos de ellas y normalmente dejan de emplearse cuando interviene un hablante monolingüe de castellano. La mejora de las comunicaciones que se ha dado en el país a partir de la década de 1940 ha ido disminuyendo el aislamiento que en otros tiempos mantenía a sus hablantes libres de influencias externas.

\section{Influencias de las lenguas indígenas}

Al tratar el tema de las influencias de las lenguas indígenas del Área Colombianocentroamericana en el español conviene distinguir entre las que se dan en el habla de las etnias mayoritarias hispanoamericanas monolingües en castellano desde que se originaron al establecerse los primeros españoles, y las que se presentan en los dialectos étnicos. Estos últimos son variedades del español originalmente desarrolladas como producto de su uso como segunda lengua por una etnia indígena y restringidas a ella. Aunque los dialectos étnicos provienen de este tipo de bilingüismo, en algunos casos, debido a la extinción del idioma indígena, llegan a constituirse en lenguas maternas de las etnias respectivas.

En las hablas de las etnias hispanoamericanas originadas desde la llegada de los conquistadores españoles, que podríamos llamar dialectos comunes, la influencia se da normalmente en el léxico, y solo excepcionalmente en algún otro aspecto (casi siempre en la morfología derivativa y, en menor grado, en la fonología). En estos casos, quienes sirvieron como punto de partida, fueron fundamentalmente personas con el castellano como primera lengua, tanto monolingües como bilingües poseedores de distintos grado de dominio de la lengua indígena como segunda lengua. Este tipo de personas introdujeron préstamos básicamente destinados, en la mayoría de los casos, a llenar lagunas que el castellano tenía por su condición ajena al mundo americano (los llamados tradicionalmente préstamos motivados por la necesidad).

Las influencias de las lenguas indígenas que se dan en los dialectos étnicos son, lógicamente, mucho mayores y con frecuencia abarcan todos los niveles de la lengua. Esta intensidad notablemente mayor de las influencias se debe a que en el caso de los dialectos étnicos el punto de partida son personas bilingües que tienen un dominio completo de su lengua materna indígena y uno parcial del castellano e introducen en este elementos de aquella para llenar lagunas más que nada debidas a su conocimiento incompleto.

\subsection{Influencia de las lenguas indígenas en el castellano común de Costa Rica}

Ha habido tendencias diferentes en cuanto a las relaciones del castellano y las lenguas indígenas durante los cinco siglos en que han estado en contacto. En un trabajo sobre esta temática (Constenla Umaña 2007), propuse, para el caso de los dialectos comunes, las siguientes etapas para dichas relaciones en la Baja Centroamérica. 


\subsubsection{Siglos XVI y XVII: Ocupación de los territorios de los grupos indígenas más poderosos}

Los conquistadores percibieron claramente cuáles eran los grupos indígenas más importantes y le dieron prioridad a la conquista de sus territorios: en el caso de Costa Rica, a la del territorio huetar.

Las conquistas mencionadas decidieron lo que iba a ser la situación lingüística del área durante los siglos XVI y XVII. En una etapa inicial, cuando todavía la mayor parte de los conquistados no había aprendido la lengua de los conquistadores, los idiomas nativos más importantes sirvieron de medio de comunicación con los indígenas en general y se emplearon para inculcarles las ideas y el modo de vida hispánicos. Poco a poco, debido a factores como una mayor presencia de españoles, el mestizaje y las disposiciones legales asimilacionistas se fue generalizando el bilingüismo y el castellano fue desplazando a dichos idiomas en cada vez más y más esferas comunicativas. A fines del siglo XVII, las que habían servido como lenguas francas en época precolombina habían perdido su condición de tales y se encontraban en claro retroceso aun dentro de sus mismos territorios.

En la historia de la convivencia de las lenguas indígenas y el castellano, desde el punto de vista de este último, esta fue la etapa de mayor interacción, aquella en que hubo más hispanohablantes que aprendieran lenguas indígenas y también aquella en que se dieron las mayores influencias lingüísticas sobre ellos.

\subsubsection{Siglos XVIII, XIX: Aislamiento de los indígenas no sometidos en regiones de refugio}

Durante los siglos XVIII y XIX, la expansión de la población hispánica a nuevas zonas fue escasa y lenta. Áreas como la parte sur del Caribe costarricense y las llanuras de Guatuso se mantuvieron en alto grado libres del control hispánico y se constituyeron en regiones de refugio de grupos indígenas, lo cual favoreció la conservación de sus lenguas y de sus culturas.

La castellanización creciente y en algunos casos total de los territorios que habían sido de las lenguas generales (en el siglo XVIII, en nuestro caso desapareció el huetar) y el aislamiento de las otras lenguas en regiones de refugio determinaron que esta fuera la etapa de menor interacción entre el castellano y las lenguas indígenas, y de menor influencia de estas sobre aquel.

\subsubsection{Siglo XX: Desaparición de las regiones de refugio}

En el transcurso del siglo XX, más temprano en algunos sitios, más tarde en otros, las regiones de refugio dejaron de serlo o disminuyeron en mucho su tamaño. La penetración intensa de los hispanohablantes en ellas ha significado una interacción mayor entre el castellano y las lenguas indígenas.

\subsection{Tipos de préstamos en las distintas etapas}

En los dialectos comunes, los préstamos procedentes de las lenguas del área se limitan al parecer al léxico (no conozco ningún rasgo gramatical o fonológico que se haya demostrado claramente que se derive de la influencia de alguna de ellas) y hay una correlación entre el tipo de elementos incorporados con las etapas de la convivencia planteadas anteriormente y con la importancia de las lenguas para la época del descubrimiento. Este hecho es reconocido 
de manera general. El lingüista español De Granda, por ejemplo, en su zonificación de Hispanoamérica según el grado de influencia de las lenguas indígenas sobre el español, incluye a la Baja Centroamérica en una de las áreas en que esta fue mínima y limitada al léxico.

Dejando de lado los topónimos, la cantidad más importante de préstamos está integrada por sustantivos de las clases de los zoónimos y los fitónimos, elementos que normalmente se tomaron de las lenguas más importantes empleadas como lenguas francas en la primera etapa, lo cual es natural, pues entonces el castellano no había acabado de llenar las lagunas de su léxico en lo relativo a la naturaleza americana. En esa época, se adoptó también una cantidad muy exigua de adjetivos entre los que predominan los referentes a estados de plantas o de cosas elaboradas a partir de ellas.

Tanto en la primera etapa como en las dos siguientes se han adoptado otros tipos de sustantivos: antropónimos, gentilicios, nombres de lenguas, nombres comunes de tipos de seres sobrenaturales y nombres propios de estos, nombres de cargos y nombres de objetos característicos de las culturas. En la primera etapa, la inmensa mayoría de estos elementos se tomó de las lenguas generales; en las siguientes, el desuso de las lenguas generales fuera de sus territorios propios y su extinción en estos han determinado que se hayan tomado de las lenguas locales de las regiones de refugio.

Los topónimos son la única categoría que compite en vitalidad y supera en número a los zoónimos y fitónimos. El siglo XVI, el último tercio del siglo XIX y los dos primeros del siglo XX, han sido los momentos más intensos de su adopción. En el último tercio del siglo $\mathrm{XX}$, la cantidad de topónimos tomados en préstamo ha decrecido notablemente.

A partir del último tercio del siglo XIX, los gentilicios principales de los pueblos indígenas y los nombres de sus lenguas han presentado una gran inestabilidad que ha llevado a constantes nuevas adopciones. El motivo es, por lo general, que los antropólogos, los lingüistas o, más recientemente, los dirigentes indígenas deciden en determinado momento cambiar la denominación usada hasta el momento, con frecuencia empleando el argumento de que no es el "verdadero nombre" del pueblo o la lengua; es así como a una de las lenguas chibchenses de Colombia se la ha conocido con los nombres de guamaca, sanká, sanjá, arsario, marocacero, malayo y damana, y en lugar de guaimí y guatuso, muchos prefieren actualmente decir nobere (aunque escriban ngäbere, de acuerdo con la ortografía práctica oficial de la lengua) y malecu. Otro tipo de gentilicios, los que designan a subgrupos en que se dividen las etnias, como, por ejemplo, los nombres de clanes, se toman en préstamo, pero casi únicamente en obras que tratan sobre sus culturas o en traducciones de textos indígenas.

El uso abundante pero, en general, totalmente transitorio de antropónimos nativos para hacer referencia a los indígenas, que apenas estaban empezando a adquirir nombres y apellidos españoles fue algo propio de la primera etapa; en las siguientes, ha sido extremadamente ocasional y limitado más que nada a trabajos especializados como los etnográficos.

Los nombres de tipos de seres sobrenaturales y nombres propios de estos, los nombres de cargos y los nombres de objetos característicos de las culturas siguen tomándose en préstamo, pero su uso está más que nada limitado a las personas que se relacionan con los indígenas, principalmente desde el punto de vista del estudio de su cultura y su historia o a las traducciones de textos indígenas.

Con muy pocas excepciones, la pertenencia a vocabularios conocidos solamente por minorías, de todos modos, parece ser cada vez más el destino de los préstamos de las lenguas indígenas probablemente en toda América. Esto ha llegado a ocurrir incluso con los fitónimos y zoónimos, propios del habla de la población rural, que pasó en el siglo XX de ser mayoritaria 
a minoritaria. Obviamente esta es la causa de la escasa vitalidad mostrada por los indigenismos en general en los estudios que se han realizado al respecto, que han sido llevados a cabo en centros urbanos al parecer en todos los casos.

Lo anteriormente señalado se cumple totalmente en el caso de Costa Rica. En la primera etapa, el castellano tuvo sus mayores contactos con el huetar y el chorotega. La cantidad mayor de préstamos de origen indígena local que se dan en él provienen del huetar y fueron en la primera etapa de la convivencia. Estos incluyen, en primer lugar, una cantidad muy grande de topónimos como los siguientes cuyo uso intenso se ha prolongado hasta la actualidad:

Aserrí, Agres, Aquiares, Arribará, Birrís, Caraigres, Cariogres, Cirrí, Coris, Corrogres, Cucubres, Chicuá, Chires, Chirobres, Chures, Escazú, Guararí, Güicasí, Irrires, Itiquís, Jaris, Orobres, Paires, Patarrá, Picagres, Pigres, Pirrís, Porrosatí, Purires, Puruces, Purisil, Quercuá, Quitirricí, Siquiares, Siquirres, Surubres, Tacares, Tapantí, Taras, Tarbaca, Tatiscú, Ticufres, Tiquires, Tocorí, Toyogres, Túfares, Tuis, Turrós, Turrubares, Turrúcares, Tusubres, Urases, Urasca, Uriche, Yacuares.

Los antropónimos tomados del huetar, como era de esperarse, se emplearon más que nada en la época en que vivían los personajes denominados por su medio; luego aparecen ocasionalmente en escritos históricos más que nada al hacer referencia a ellos (la mayor parte eran nombres de personajes importantes). Algunos ejemplos son: Aquitaba, Ayarro, Bariaba, Caricabi, Chobor, Pacaba, Pixtoro, Tayecara y Toracci.

Además de los topónimos, existe una serie de nombres comunes, casi todos ellos denominaciones de especies animales y vegetales propias del área. Ejemplos de fitónimos del tipo que se están comentando son los siguientes: ascá, buriogre, cocora, cubá, curraré, chirra, erepe, guagra, guarrazú, güízaro, jucó, poró, pu, putarrá, quiquicirrí, quitirrí, súrtuba, surubre, targuá, terré, tora, tuete, turrusí, yas, yos.

Algunos nombres de especies zoológicas son: arragre (tipo de abeja silvestre), béquer (tipo de serpiente), capasurí (venado que tiene los cuernos cubiertos por la piel, recogido en Gagini 1918, en desuso actualmente), cosorró (pájaro carpintero), cuascuasa (tipo de cangrejo), cusinga (tipo de tucán), icí (en zorro icí o zorricí), oropopo (tipo de búho), quioro (tipo de tucán), pirrís (tipo de pájaro), purruja (tipo de mosquito), soterré (tipo de pájaro), yárreco (tipo de cangrejo), yerre (tipo de gallina de monte), yigüirro (tipo de tordo), yuré (tipo de paloma).

Existen algunos nombres comunes pertenencientes a otras áreas de significado, como usú 'hueco, cueva', yurro 'manantial', tiquí 'calabazo grande para el agua', voto o boto 'indígena rama'. En el caso de los nombres de cargos o posiciones sociales, como taque 'cacique de menor rango', uri 'hijo de señor principal', sucedió algo semejante a lo ocurrido en el de los antropónimos: se emplearon en las descripciones de la sociedad huetar por parte de los cronistas de la conquista y luego se han seguido mencionando en las obras históricas. Fuera de sustantivos, solo se tomó en préstamo algún adjetivo como urrú 'apolillado'.

En la primera etapa, también se incorporaron en el español de Guanacaste vocablos chorotegas, pero, seguramente por no ser esta una lengua general, el número de estos elementos fue muy bajo, aun en el caso de los topónimos entre los que podemos citar Curime, Diriá (ndiri 'colina'), Nandayure (probablemente 'quebrada de aves'; nanda 'quebrada', yure 'ave'), Nambi (nambí 'perro'), Nimboyores (quizás 'agua de aves'; nimbo 'agua', yure 'ave' o 'agua fría' nimbu yoro 'agua fría'). Quesada Pacheco en su libro de 1991 sobre el español de Guanacaste señala que solo encontró tres nombres comunes con etimología chorotega: nacume 'mayordomo de la 
cofradía de la Virgen de Guadalupe en Nicoya', nambiro 'calabaza grande para llevar agua' y nimbuera 'olla o puchero mediano'.

Por lo que respecta a los nahuas, Quesada Pacheco plantea acertadamente lo siguiente:

\begin{abstract}
Quizás con excepción de la palabra Tempisque, cuya presencia en la provincia de Guanacaste está documentada desde inicios de la Colonia, el náhuatl en Costa Rica no ha dejado huellas en la toponimia costarricense. Ahora bien, existe una mal fundada idea de que nombres de origen náhuatl como Guanacaste, Jicaral, Zapote, Los Chiles, Guápiles, Montezuma, Chagüite y tantos otros que abundan en calidad de toponímicos en Costa Rica, son testimonio de la presencia de los aztecas de época antigua (cfr. Ferrero 1986: 100-101). Lo cierto es que estas palabras dieron nombres a muchos lugares del país a través de la lengua española; es decir, comenzaron a actuar como topónimos una vez incluidos en el vocabulario patrimonial castellano. (2006: 213)
\end{abstract}

Lo anterior no tiene nada de extraño si se toma en cuenta lo pequeña que fue la población de lengua nahua y su falta de importancia en la Costa Rica precolombina.

Desde la primera etapa se toman también préstamos de las lenguas originarias del sur del país: el boruca, el bribri y el cabécar. Estos préstamos son en general nombres propios, topónimos y antropónimos, pero también se toman nombres comunes del tipo más afín a los propios: gentilicios. A partir de la segunda, se toman, pero como se señaló antes más que nada en el habla especializada de los estudiosos de las culturas, otros tipos de sustantivos vinculados directamente con aspectos de estas: primero nombres de cargos y nombres de objetos característicos, luego nombres comunes de tipos de seres sobrenaturales y nombres propios de estos.

En el caso del boruca, se ha adoptado cierta cantidad de topónimos como Boruca ( $<$ /brúnkàxk/, documentado desde la primera etapa, primero como Borucaca o Burucaca), Ruchen, Castan, Gridum, Sicanche, Bruncrin, Bujerá, Dutú, Canchen y Yan. Quesada (2006) clasifica como de dicho origen a una veintena de los que incluye. Durante la primera etapa se emplearon antropónimos como Xiriara (cacique de Turucaca y Boruca) y Guayaví (cacique de Boruca) y en la tercera, en narraciones en castellano se ha observado el uso de nombres de personajes tanto puramente humanos como Seredrún y Suatuj (unos suquias o chamanes), como de "encantos" como Cuasrán, Sancrahua y las Mamrán. En cuanto a nombres comunes, en la primera época se adoptó el gentilicio texbi (</tífbì?/) “térraba/teribe”, pero en las etapas posteriores no he observado el uso de palabras de origen boruca ni siquiera en obras especializadas para referirse, por ejemplo, a oficios característicos de la cultura.

En el caso del bribri y del cabécar, desde la primera etapa se han tomado en préstamo topónimos que, sobre todo durante la tercera etapa, han pasado a ser una cantidad muy considerable (en Quesada Pacheco, 2006, los topónimos considerados de origen bribri y cabécar suman un 58\% del total de los tomados en cuenta); se trata, para citar algunos de nombres como Ambri Amubri, Blorikal, Bitey, Coen, Coroma, Cuabrí, Chin Beta, Chumuri, Dipali, Dlora, Hobri, Katsi, Kàmuk, Lari, Namú-Uorkíbeta, Purisqui, Quichúguecha, Sepecue, Soki, Suretka, Telire, Tsiúrabeta, Urén y Yuabin (bribris), y Bolorí, Bururak, Calveri, China Kichá, Dikeclari, Duchí, Jakbarari, Juclori, Kabébeta, Kukarí, Mururbi Suk, Nackleri, Piste, Shararí, Shukebacharí, Simarí, Surari, Suruy, Tapardí y Tsimari (cabécares).

Durante la primera etapa se emplearon antropónimos bribris como Quirigrama, nombre del "cacique principal de los altos de Viceíta" (Lehmann 1920: 232) y cabécares como Xora cacique que dirigió una rebelión en el área de Chirripó y el río Matina y Presbere (dirigente de la más afamada de las rebeliones talamanqueñas). En la tercera, en versiones en castellano de la literatura oral y en descripciones etnográficas, aparecen numerosos nombres de seres sobrenaturales tanto bribris -Tsaítamin, diosa de cuyo cadáver surgió el árbol que al 
ser talado dio origen al mar; $O^{\prime} k \underline{a m} \underline{a}$, dios poseedor de herramientas metálicas, y Shulè kama dios tutelar de las serpientes- como los cabécares -Míkö, diablo con aspecto de mujer que deambula por el monte, y Sérikë, espíritu de las tormentas.

Durante la primera y la segunda etapas se emplearon los gentilicios terbi (probablemente del bribri [tîrù b]) “térraba/teribe”), cabécara (del cabécar [kàbékàrà]), que terminó adoptándose definitivamente sin la $a$ final, y térraba (del cabécar [tírbà], término que actualmente se conserva más que nada en el habla ritual).

En la segunda época, en descripciones hechas por frailes, se usaron términos referentes a cargos como capar (</kàpâ/, sinónimo bribri de usécar, de acuerdo con Bozzoli 2006 'máxima autoridad religiosa' e isogro (del cabécar [ksúgIư]) 'cantor de funerales', pero es en la tercera, que en obras especializadas aparecen, entre otros nombres comunes, los de los clanes como tu'bölwak, tkabëriwak, síbawak, sula'riwak y dìuwak (bribris), como tugwák, kibéilowák, kotwák (cabécares), los de cargos como óköb 'hombre a cargo de la manipulación de los cadáveres', bikâkala 'maestro de ceremonias' (en bribri) y jawá 'médico-chamán' (en cabécar), y los de diversos otros elementos culturales como los denotados por las palabras bribris áknama 'espíritu perjudicial que tiene que ver con las enfermedades', sulàr 'fiesta parte del ritual funerario' y dulè 'un tipo de canto que se interpreta en las fiestas solo para ser escuchado' o el lexema cabécar kipö ksé 'canto de cuna'. Todos estos vocablos suelen escribirse empleando algún alfabeto práctico de la lengua de que se trate, pero los hispanohablantes al emplearlas oscilan entre la pronunciación correcta en ella y pronunciaciones con diverso grado de adaptación al castellano incluyendo la total.

De los hablantes de rama, votos y corobicíes, se tomaron en la primera etapa topónimos como Jori (que se usó solo durante ella), Sarapiquí y Corobicí, y antropónimos como Pocica y Pisisara. Posteriormente, al parecer no se incorporaron al castellano más préstamos de esta procedencia.

La situación en el caso de sus vecinos en la Zona Norte, los guatusos, es completamente la inversa. De la lengua de estos no se comenzó a tomar préstamos sino a finales de la segunda etapa. Es en las crónicas de las visitas del obispo Thiel en esa época en las que comienzan a aparecer castellanizaciones de topónimos guatusos como Onafi (/ona:фij/) 'río La Cucaracha', Catinure (/katurnure:/) 'río Catanurio', Tojifo (/to:xiфa:/) 'río El Sol' (también llamado Tonjibe o Tojíbar) y de conceptos propios de la cultura como Tocu 'Dios' (/to:ku/ 'dios'), sabará (/

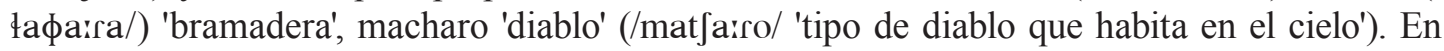
la tercera etapa, de los topónimos se ha consolidado el uso de por lo menos los siguientes 10: Cabanga ( $</$ kaфạka/ 'alcotán', nombre dado por los guatusos al lugar debido a la abundancia

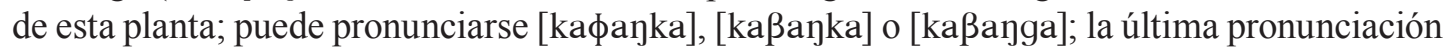
coincide con la palabra delcastellano local cabanga), Catanurio $(</$ katuinur $/ \sim(/$ katuinure: $/)$, Cote o Cóter ( $</$ ko:te/), Curirre ( $</$ kuri:re/), Quéquir o Quéquer $(</$ ke:ki/), Samen $(</$ la:mi/), Tiales $(</$ tia:li/), Timácar o Timacar $(</$ tima:kar/ $\sim /$ tima:kara: $/)$, Tonjibe o Tojíbar $(</$ to:xi $\phi / \sim$ / to:xiфa:/), Upala (</urpal/ / urpala:/).

En esta etapa, se ha adoptado el gentilicio malecu "indígena guatuso" ( $<$ /malerku/ 'persona de las nuestras'), que se emplea también como denominación de la lengua guatusa, y en traducciones al castellano de narraciones tradicionales y obras especializadas aparecen nombres propios tanto de personajes humanos como sobrenaturales y algunos nombres comunes que designan objetos o entidades propios de la cultura: Colúrinh (hombre que viajó al lugar de castigo situado en el cielo), Jafára (hija del jefe de los dioses), Oronhcafá (demonio principal 
del lugar de castigo del cielo), marácunúca 'narración tradicional', mayupéca 'duelo verbal', y cocálúrinh 'persona que está en estado de gracia de acuerdo con la religión tradicional y que, en consecuencia, no puede tener muerte violenta'. De manera semejante a lo que ocurre en bribri y en cabécar, los lexemas en cuestión se escriben en la ortografía de la lengua reconocida por el Ministerio de Educación y se pronuncian con diverso grado de adaptación al castellano.

En el caso de la variedad térraba de la lengua naso, establecida en Costa Rica, como se señaló antes, por una inmigración desde Panamá ocurrida a fines del siglo XVII, las contribuciones al castellano de Costa Rica parecen ser sumamente limitadas. Quesada Pacheco (2006) le atribuye origen térraba a solo 3 de los 496 topónimos que toma en cuenta: Carse, Dobóncrahua y Dobonde (los dos últimos formados a partir de [dòbóy] 'felino'). A estos podrían añadirse Di Bocuo (</dí bócuò/ 'ojo de agua', localidad situada entre las poblaciones de Santa Eduviges y Las Brisas, en el camino a San Rafael de Cabagra) y Diquís (</díkís/ 'río grande'), nombre alternativo del Río Grande de Térraba. No se ha observado el uso de nombres comunes procedentes de esta lengua ni siquiera en obras especializadas.

La lengua guaimí, introducida por migraciones demasiado recientes, de acuerdo con Quesada Pacheco (2006: 212): "no ha dejado huellas en la toponimia costarricense". Los únicos elementos que se ha tomado en préstamo en el castellano de este país son el gentilicio /jobe/ 'indígena guaimí' y el nombre de la lengua derivado de él /yəbere/. Las adaptaciones más viejas de ambos en castellano son respectivamente move y movere (hechas originalmente en Panamá y usadas por costarricenses en algunos trabajos especializados), pero actualmente predominan en el español de Costa Rica /'nobe/ y /no'bere/, generalmente escritas ngäbe y ngäbere de acuerdo con la ortografía oficial de la lengua o ngöbe y ngöbere, a contrapelo de ella.

\section{Notas}

1. Debo aclarar que he interpretado el término indígena no como lo define el Diccionario de la Lengua Española en su última edición "originario del país de que se trata" sino de acuerdo con el significado que se le da más frecuentemente en Hispanoamérica "perteneciente a una de las etnias que ya estaban establecidas en América antes de 1492", esto es como sinónimo de amerindio y de indoamericano.

\section{Bibliografía}

Bauman, James J. 1980. A guide to issues in Indian language retention. Washington D.C.: Center for Applied Linguistics.

Bozzoli de Wille, María Eugenia. 2006. Oí decir del usékar. San José: EUNED.

Brown, Keith (Ed.) 2006. Encyclopedia of Language and Linguistics. Vol. 3. (2 ${ }^{\text {da }}$ ed.). London: Elsevier.

Constenla Umaña, Adolfo. 1995. "Sobre el estudio de las lenguas chibchenses y su contribución al conocimiento del pasado de sus hablantes". Museo del Oro. 38-39: 13-55.

2005. "Acerca de la relación genealógica entre las lenguas misumalpas y las chibchenses". Estudios de Lingüística Chibcha. 23: 9-89. 
2006. “Costa Rica: Language Situation”. En: Brown (Ed.): 256-257.

2007. "Efectos de la convivencia del castellano y las lenguas indígenas en el Área Colombiano-centroamericana (Baja Centroamérica)". Ponencia presentada en el IV Congreso Internacional de la Lengua Española. Cartagena de Indias, del 26 al 29 de marzo.

2008. "Estado actual de la subclasificación de las lenguas chibchenses y de la reconstrucción fonológica y gramatical del protochibchense". Estudios de Lingüística Chibcha. 27: 117-135.

Dyen, Isadore. 1956. "Language distribution and migration theory". Language. 35: 611-626.

Gagini, Carlos. 1918. Diccionario de costarriqueñismos. San José: Tipografía Nacional.

Granda, Germán de. 2001. "El influjo de las lenguas indoamericanas sobre el español. Un modelo interpretativo sociohistórico de variantes areales de contacto lingüístico". Estudios de Lingüística Andina, 9-35.

Greenberg, Joseph. 1987. Language in the Americas. Stanford: Stanford University Press.

Holt, Dennis. 1986. The Development of the Paya Sound System. Tesis doctoral: Universidad de California.

Jijón y Caamaño, Jacinto. 1943. El Ecuador Interandino y Occidental, Vol. 3: Las lenguas del sur de Centro-América y el norte y centro del Oeste de Sud-América. Quito: Editorial Ecuatoriana.

Kaufman, Terrence. 1974. Idiomas de Mesoamérica. Guatemala: Ministerio de Educación.

Lehmann, Walter. 1920. Zentral-Amerika. Teil I. Die Sprachen Zentral-Amerikas. Vol. I. Berlín: Verlag Dietrich Reimer.

Quesada Pacheco, Miguel Ángel. 1991. El español de Guanacaste. San José: Editorial de la Universidad de Costa Rica.

2006. “Toponimia indígena de Costa Rica”. Revista de Filología y Lingüística. 32 (2): 203-259.

Quirós Rodríguez, Juan Santiago. 1984. La lengua chorotega o mangue: análisis lingüístico de los materiales existentes. Tesis de licenciatura: Universidad de Costa Rica.

Schuller, Rudolf. 1919-1920. “Zur sprachlichen Verwandtschaft der Maya-Qu 'itše mit CaribAruác”. Anthropos. 14/15: 465-91.

Thiel, Bernardo Augusto. 1927. Viajes a varias partes de la República de Costa Rica. San José: Imprenta y Librería Trejos Hermanos. 